Association for Information Systems AIS Electronic Library (AISeL)

ICIS 1989 Proceedings

International Conference on Information Systems

1989

\title{
A PROCESS MODEL FOR THE CONTROL OF INFORMATION SYSTEM DEVELOPMENT PROJECTS
}

Michael Newman

Florida International University

Rajiv Sabherwal

Florida International University

Follow this and additional works at: http://aisel.aisnet.org/icis1989

\section{Recommended Citation}

Newman, Michael and Sabherwal, Rajiv, "A PROCESS MODEL FOR THE CONTROL OF INFORMATION SYSTEM DEVELOPMENT PROJECTS" (1989). ICIS 1989 Proceedings. 49.

http://aisel.aisnet.org/icis1989/49

This material is brought to you by the International Conference on Information Systems (ICIS) at AIS Electronic Library (AISeL). It has been accepted for inclusion in ICIS 1989 Proceedings by an authorized administrator of AIS Electronic Library (AISeL). For more information, please contact elibrary@aisnet.org. 


\title{
A PROCESS MODEL FOR THE CONTROL OF INFORMATION SYSTEM DEVELOPMENT PROJECTS
}

\author{
Michael Newman \\ Rajiv Sabherwal \\ Decision Sciences Department \\ Florida International University
}

\begin{abstract}
A process model to portray the dynamics of Information Systems Development (ISD) is presented. The model, while primarily rooted in earlier process models, also incorporates two key contextual factors -- the perceived threat to users and the relative power of the users and the systems group -from past factor studies. The model is then used to generate four scenarios across the ISD process. These are co-operative, user-dominated, MIS-dominated, and conflict. The scenarios are illustrated with summaries from recent case studies in ISD. This indicates the effectiveness of the model. The paper concludes with suggestions for using the model to identify the relevant scenario and thereby improve the management of the ISD process.
\end{abstract}

\section{INTRODUCTION}

While the viability of major corporations depends on their continued technologicalinnovativeness, informationsystems development (ISD), so vital to numerous innovations, continues to cause many problems. Large-scale catastrophic failures have been witnessed in this area and many systems have failed to meet their potential (Lucas 1975; Lyytinen and Hirschheim 1987; Hirschheim and Newman 1988). The survey by Gladden (1982) indicated the scope and hence the economic consequences of these failures. He estimated that 75 percent of all projects are either never completed or, if completed, only partially used.

It is generally accepted that to treat ISD only as a technical task is inadequate. The interaction between users and systems professionals in such activities as obtaining user requirements, prototyping, and project meetings necessitates serious consideration of the social and political nature of system development. Focusing on the technical issues at the cost of such social processes inhibits understanding the complexity of ISD. Moreover, appeals to simplistic "folklore" such as "involve the users," "overcome resistance," or "get top-management support," while simplifying the designer's task, conceal the social nature of ISD and highlight the inadequacy of assumptions concerning users and organizations commonly held by designers (Newman 1988).

An examination of ISD research reveals two major approaches: factor studies and process models. In factor studies, the researcher identifies certain treatments or independent variables such as "user involvement," "top management support," and the system's "technical quality." These independent variables are then linked in a simple causal model to output measures of "success," the dependent variables. "System usage," "user satisfaction," and "staff turnover" are examples of such dependent variables. Factor studies commonly use correlation coefficients or $\mathrm{R}^{2}$ values from a survey to link the independent and dependent variables.

The process models for studying ISD, on the other hand, emphasize the interaction of social actors during the project. These interactions can result in commitments, such as sign-off procedures, or behavior, such as resistance, which may constrain subsequent behavior. The resolution of specific incidents can be vital to the project's progress (Cobb 1984; Newman 1988). If conflict between user groups is allowed to proliferate, for example, the project may get derailed or become fragmented as user groups struggle for control. Moreover, it may not be possible to identify when a project is complete. In contrast, other cases may be characterized by a high level of co-operation between the different parties. Process models also emphasize the context of the project. Thus the history of relations between systems and user groups is often vital to understanding the course of the project. Also important are the organizational characteristics and other factors such as the displacement or resignation of key actors during the process (Newman and Noble 1988).

The use of process models thus implies a dynamic perspective of the ISD process, in contrast to the primarily static view taken by factor research. It incorporates the interaction between users, developers, and other actors and emphasizes that the nature of such interaction may change significantly during the system development process. A similar point has been recently made by Tait and Vessey (1988) who, finding only a weak association between user involvement and success, call for more longitudinal research to adequately capture the dynamics of the process. Moreover, the measure of "success" can be highly problematic in factor studies. Success is a suspect term in 
conflictual situations, as it depends on whether the evaluator is on the winning or the losing side (Newman and Noble 1988).

There is clearly a need for a process model for ISD projects. However, a unique characterization of the ISD process is not justified since the process would differ due to differences in a number of contextual conditions (Cobb 1984). Depending on the nature of the system and its effect on the users, and the relative power that the users and MIS have over the system, the MIS project might vary from a highly rational and co-operative process on one extreme to a conflictual, acutely political process on the other.

The context of ISD is a major area of attention in factor studies. For describing the context in which the ISD process takes place, we can draw upon such studies. In our process model, two factors that have received considerable attention in factor research -- the extent to which the information system is perceived as a threat by the users and the relative power of systems and users -- have been therefore utilized to portray the context for the ISD project. ${ }^{1}$ These contextual factors are discussed in the beginning of the next section.

It needs to be pointed out that these contextual factors are themselves dynamic. Thus an ISD project might start off with the users considering the system as highly beneficial, but at a later stage in the ISD process they might start viewing it as a threat. Moreover, the nature of the ISD process may also be affected by such a change in a key contextual factor.

In the next section, we develop a process model for ISD projects. Using this model, which incorporates the two contextual factors, we explicate four possible "pure" scenarios. These scenarios range from a co-operative strategy to one where consensus is absent and a struggle for control is encountered. Section 3 illustrates the process model using evidence from case studies. Finally some implications of this approach are discussed in Section 4.

\section{THE PROCESS MODEL}

\subsection{The Contextual Factors}

\subsubsection{Perceived Threat to Users}

The behavior of users during the MIS project depends on whether or not they perceive the system to be a threat. The following four key factors have been mentioned in the literature as determining the way users perceive the system.

a) Uncertainty: When the system has considerable uncertainty associated with it, the users may fear losing their jobs or being transferred, having an increased work- load, being unable to acquire the needed new skills, or losing status and prestige (Hirschheim and Newman 1988). It does not really matter if the system actually affects the users or not but only whether they feel uncertain about its implications (Saunders 1981).

b) Conscious attempts to control: The users might believe that the top-management, MIS, or some other department in the company are using the system as a vehicle for redistributing power and resources such as information, equipment, staff and budgets (Bariff and Galbraith 1978; Hirschheim and Newman 1988; Markus 1983). Such perceived attempts by others in the company to control valuable resources may also threaten the users.

c) Organizational invalidity: There may be a mismatch between system design features and the existing organizational characteristics, such as the organizational culture and paradigm, the other sources of power (Markus and Pfeffer 1983). When the system lacks "organizational validity" (Markus and Robey 1983), it would pose a threat to the users whether they recognize it or not (Hirschheim and Newman 1988; Markus 1983).

d) Historical factors: The users' past experience with MIS may also impact their perception of any new information system. If they feel that in the earlier systems MIS and other groups shifted some power and resources away from them, then this patterning of effects may result in their feeling threatened by the new system as well. Cobb (1984), in discussing an "episodic model of power," has similarly considered one episode as influencing later episodes.

\subsubsection{Relative Power of MIS and Users}

While the nature of the system has a considerable effect on the ISD process, the relative power of users and MIS also influences the process (Markus and Bjørn-Andersen 1987). For example, if a user group perceives a system as highly threatening, it may try to oppose the system actively and try to get it discontinued if the group is more powerful than the advocates of the system (usually including MIS). On the other hand, if it has much less power than the MIS, it may resort to more covert methods of resistance, or may participate passively.

Numerous authors have discussed the various sources of power and their implications for relative power of MIS and users. Based on an extensive literature search, we have selected five key sources of power which are briefly discussed below. The implications of these sources for the power of MIS, the power of users, and the relative power of these two groups, are summarized in Figure 1. 


\begin{tabular}{|c|c|c|c|}
\hline Sources of Power & Implications for MIS & Implications for Users & Conclusion \\
\hline Political skilis & $\begin{array}{l}\text { MIS professionals are commonly believed to be } \\
\text { politically naive, though some recent studies } \\
\text { indicate that they are at least aware of and } \\
\text { inderstand politics. In general, however, MIS } \\
\text { professionals may be considered as more } \\
\text { rational/analytical and less skilled in politics. }\end{array}$ & $\begin{array}{l}\text { Users are commonly believed to be more } \\
\text { experienced in politics. They have been } \\
\text { potrayed as using their political skilis to } \\
\text { resist threatening systems. }\end{array}$ & $\begin{array}{l}\text { Generally users have } \\
\text { greater political skills. }\end{array}$ \\
\hline $\begin{array}{l}\text { Access to } \\
\text { privileged } \\
\text { information }\end{array}$ & $\begin{array}{l}\text { MIS professionals have access to information } \\
\text { about user departments only to the extent the } \\
\text { users are willing to reveal it. }\end{array}$ & $\begin{array}{l}\text { Users are central to the flow of relevant } \\
\text { information and thus are more likely than } \\
\text { MIS, to have access to privileged } \\
\text { information. }\end{array}$ & $\begin{array}{l}\text { Users usually have } \\
\text { greater access to } \\
\text { privileged information. }\end{array}$ \\
\hline $\begin{array}{l}\text { Privileged access } \\
\text { to the influential }\end{array}$ & $\begin{array}{l}\text { Being in a staff function, MIS execukives are not } \\
\text { part of the line hierarchy and have greater } \\
\text { access to the top management. }\end{array}$ & $\begin{array}{l}\text { The users, being in the line hlerarchy, } \\
\text { have to go through formal channels that } \\
\text { constrain their access to the } \\
\text { top-management. }\end{array}$ & $\begin{array}{l}\text { MiS may be expected } \\
\text { to have greater } \\
\text { privtleged access to } \\
\text { the inf luential. }\end{array}$ \\
\hline $\begin{array}{l}\text { Non- } \\
\text { substitutability }\end{array}$ & $\begin{array}{l}\text { The non-substitutability of MIS functions and } \\
\text { MIS executives is related to their expert ise and } \\
\text { to other factors such as the organization's } \\
\text { information intensity. While past research } \\
\text { indicates that MIS department is quite easily } \\
\text { replaceable, there has been no recent study in } \\
\text { this area. We feel that no general conclusions } \\
\text { can be found here. }\end{array}$ & $\begin{array}{l}\text { The non-substitutability of user } \\
\text { departments depends on the functional role } \\
\text { they are performing. }\end{array}$ & No general expectation. \\
\hline $\begin{array}{l}\text { Coping with } \\
\text { uncertainty }\end{array}$ & $\begin{array}{l}\text { One key function MIS serves is the reduction of } \\
\text { uncertainty. Therefore, MIS execut ives do help } \\
\text { cope with uncertainty. However, in the } \\
\text { day-to-day activities, since MIS is not a line } \\
\text { function, it does not directly cope with } \\
\text { uncertainty. Past research shows mixed findings. }\end{array}$ & $\begin{array}{l}\text { Boundary spanning users have greater } \\
\text { power due to this source because they play } \\
\text { a major role in coping with uncertainty } \\
\text { (Lawerence \& Lorsch, 1967). }\end{array}$ & No general conciusion. \\
\hline
\end{tabular}

Figure 1. Power Sources and Their Implications for the Relative Power of MIS and Users

a) Political will and skill: Groups could attain power due to their being better skilled in politics and/or more willing to use it. This could be because such political will and skill enhances their ability to politically use one or more of the other sources of power they may possess or because it may be the only strength they have to achieve power (Mintzberg 1983).

b) Privileged information, gatekeeping, and centrality: In information and its control lies power. Political power accrues to those who control inputs of key information into the company, through a "gatekeeper" role (Mintzberg 1983), or stand at the crossroads of important information flows within the company by being in a position of "centrality" (Hickson et al. 1971).

c) Privileged access to the influential: Direct and unique access to those with influence in the company, derived from such sources as formal authority, expertise, charisma, seniority, or reputation, also provides power to the various groups (Mintzberg 1983; Mumford and Pettigrew 1975; Newman and Noble 1988). Such influential individuals, access to whom is an important source of power, may be, for example, the CEO or the people that serve the CEO every day (such as the CEO's secretary).

d) Non-substitutability: It has been widely accepted in the literature that a person or department that is difficult to replace will have greater power than one that is not.

e) Coping with uncertainty: Those groups that cope with uncertainty, caused by technological, environmental, or other reasons, usually have considerable power in organizations (Hickson et al. 1971; Saunders 1981; Lawrence and Lorsch 1967). By coping with uncertainty, the group provides "pseudo certainty" (Hickson et al. 1971) for the other groups and achieves power through the resulting dependency.

\subsection{The Effect of the Contextual Factors on the Process Scenarios}

Some researchers have examined the effect the context has on the nature of ISD. For example, Markus and Bjørn- 
Andersen (1987) discuss the effects of designers' and users' awareness of politics on the use of power during the ISD project. The effect of the two contextual factors considered above on the process model is shown in Figure 2 and discussed below. The strategies commonly employed by the users and MIS are also briefly examined in terms of four scenarios.

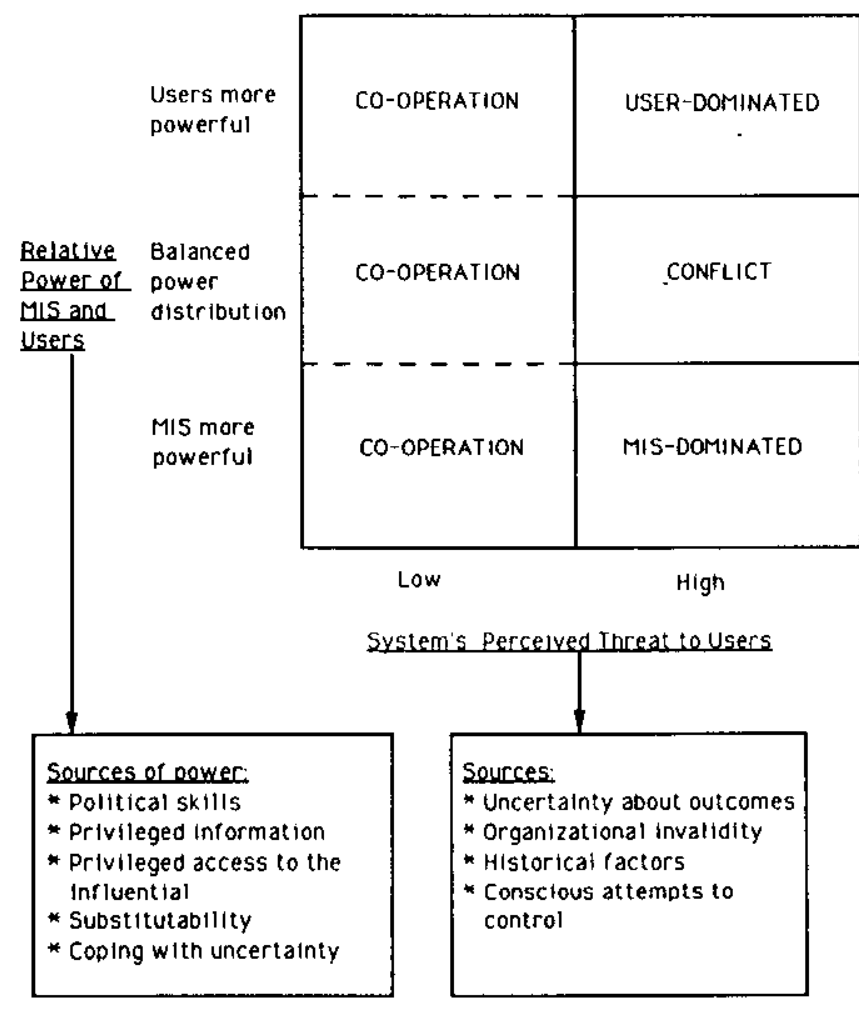

Figure 2. The Factors Affecting the Process Scenarios Appropriate for the System Life Cycle

When the project is not perceived as a threat by the users, they are likely to co-operate with the MIS department, and the process would resemble the rational model discussed in the literature, such as Boland's (1978) "traditional rationality." The key feature here is that the users and MIS co-operate, and this scenario may hence be called the co-operation scenario. The users and the MIS department work towards a system that meets the larger organizational goals. They work together, enthusiastically and creatively, aiming at the best possible system.

However, when the users perceive the system to be a threat, one of three different processes may develop depending on the relative power of users and the systems group. Thus when the systems department is more powerful than the users, the system development goes through a process which may appropriately be called MISdominated. This scenario resembles the "professional manipulation" discussed by Markus and Bjørn-Andersen
(1987). In this case the users may resist the system and try to increase their own power, for example by withholding useful information, or they may feel so powerless that they remain passive, thereby reinforcing the MIS domination. The MIS professionals, however, are very active and enthusiastic. They try to develop the system that best serves their strong professional allegiance (Mintzberg 1983). Depending on historical factors, they may take one of two approaches towards the users: they may either try to continue dominating the users or attempt to appease them through such means as increased user involvement.

On the other hand, when the users are more powerful than MIS, a user-dominated process, somewhat similar to the "user-led" model discussed by Franz and Robey (1984), may be the relevant scenario. Here the users make an active contribution to the system initiation, design, development, and implementation. However, they try to modify the system such that it meets their parochial goals and does not pose a threat. The MIS professionals are more passive in their contribution to the process. They may try to retain the initial system objectives, which the users are trying to change because of their threatening nature. On the other extreme, they may comply with the wishes of the more powerful users.

Finally, when there is a balance of power between the users and the MIS department, the process is likely to resemble the "political" model (Markus 1983; Swanson 1983). Considerable conflict may be expected here as neither party can dominate the other and they have opposite interests: users feel threatened by the system while MIS promotes it. This process scenario has therefore been labeled as the conflict scenario. The users may strongly resist the system, trying to either have it completely rejected or significantly modified (so that it becomes less threatening). On the other side, the MIS professionals may try to increase their power and force the system on the users. In some cases, the users and MIS professionals may go through mutual negotiations (Markus and Bjørn-Andersen 1987). The struggle may be overt in other cases, characterized by threats, coercion, and appeals to higher authority.

The strategies employed by the users and the systems group in each of the four process scenarios have been summarized in Figure 3.

\subsection{The Process Scenarios}

We have discussed the strategies used by the users and MIS professionals in the four process scenarios. In this section, we will look at the scenarios in greater detail, examining the tactics users and MIS professionals employ in each of the following four phases of the system project:

a) Project Proposal, which involves the conceptualization of the project, preparation of a decision on the proposal, and the commencement of the project. 
IHE CONTEXTUAL EACTORS

IHE PROCESS SCENABIOS
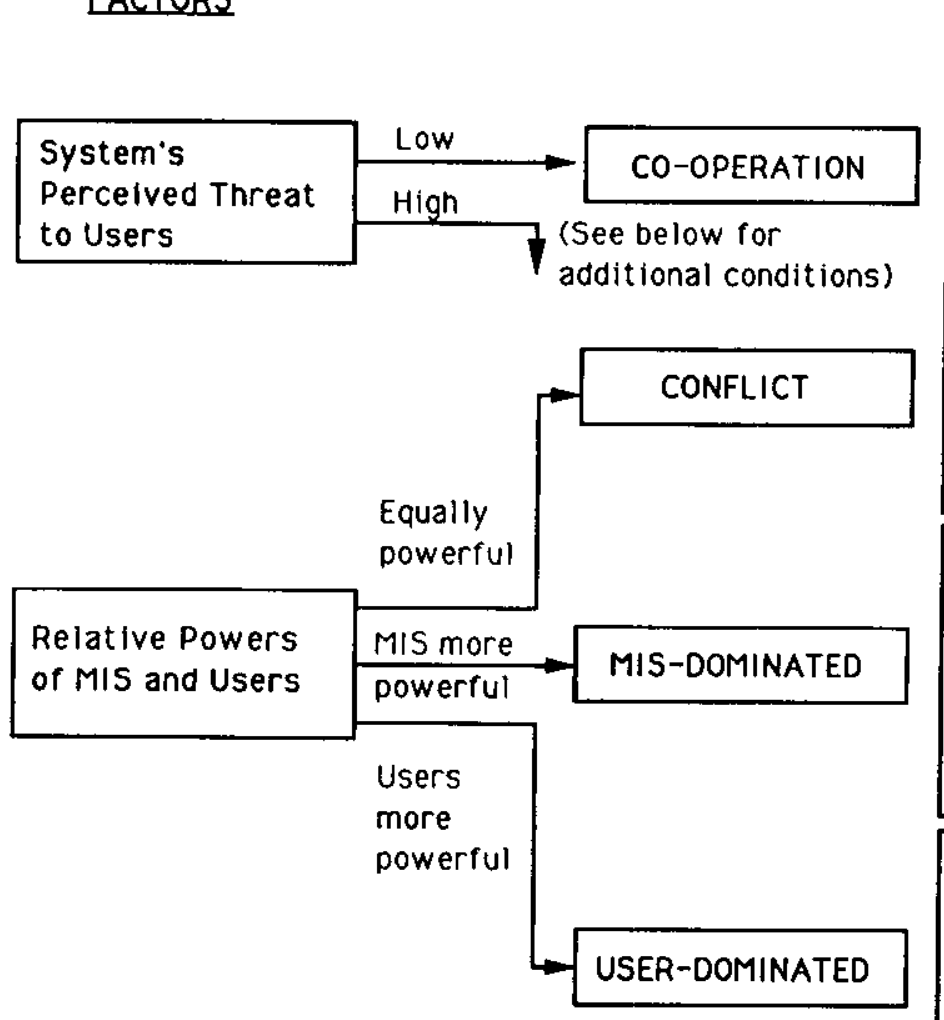

\begin{tabular}{|c|c|}
\hline \multicolumn{2}{|c|}{ IHE SIRATEGIES } \\
\hline USERS & MIS \\
\hline $\begin{array}{l}\text { Active contribution. } \\
\text { Aim for the best possible } \\
\text { system for the } \\
\text { organization. }\end{array}$ & $\begin{array}{l}\text { Active contribution. } \\
\text { Aim for the best possible } \\
\text { system for the } \\
\text { organization. }\end{array}$ \\
\hline $\begin{array}{l}\text { Active resistance. } \\
\text { Or, mutual } \\
\text { negotiation. }\end{array}$ & $\begin{array}{l}\text { May try to increase their } \\
\text { power and force the } \\
\text { system. } \\
\text { Or, may try to negotiate } \\
\text { with the users. }\end{array}$ \\
\hline $\begin{array}{l}\text { Passive contribution. } \\
\text { Try to resist where } \\
\text { possible. } \\
\text { Also try to increase their } \\
\text { power. }\end{array}$ & $\begin{array}{l}\text { Active contribution. } \\
\text { Aim for the best possible } \\
\text { system for the } \\
\text { organization. } \\
\text { May dominate users. } \\
\text { Or, may try to appease } \\
\text { them. }\end{array}$ \\
\hline $\begin{array}{l}\text { Active contribution. } \\
\text { Aim for the best possible } \\
\text { system for the } \\
\text { organization. } \\
\text { However, they try to } \\
\text { modify the system to } \\
\text { reduce its perceived } \\
\text { threat. }\end{array}$ & $\begin{array}{l}\text { Passive contribution. } \\
\text { May try to retain } \\
\text { existing system } \\
\text { objectives. } \\
\text { Or, may comply with the } \\
\text { users. } \\
\text { Also, may try to } \\
\text { increase their power. }\end{array}$ \\
\hline
\end{tabular}

Figure 3. The Process Model and Four Process Scenarios

b) MIS Design and Development, which includes the identification of user information requirements, system design, and the development of the required software.

c) MIS Implementation, which incorporates the testing of the system modules and then of the complete system, training the users to work with the system, and finally the installation and actual usage of the system.

d) MIS Evaluation, which deals with the eventual outcomes of the system and includes an assessment of its performance.

\subsubsection{Co-operative Process Scenario}

a) Project Proposal: The users contribute actively in this stage. They utilize their knowledge of the functional area to suggest a system which they consider to be the best for the company needs, while at the same time helping their own parochial needs. They work with the MIS department to assess the technical feasibility of the system and the costs involved. There is consider- able exchange of ideas between the users and MIS and they both learn from each other. The MIS professionals also contribute actively and innovatively. They use their technical expertise to suggest a system which they consider to be the best for the organization, based on the expected improvements in operational efficiency and decision-making effectiveness. They work with the users to examine the system's potential benefits.

b) MIS Design and Development: The users contribute to the requirement analysis and system design processes by providing all the information they can and do not withhold any information. They try to state their requirements clearly. They also work enthusiastically with the prototype (if one is used) and provide valuable suggestions to improve the eventual system. The MIS professionals conduct the analysis rationally, eliciting the user requirements and needs, and design the system such that it meets these requirements and provides the users with the desired benefits. They also involve users in the process to try and improve the eventual system, and may use prototyping to effectively obtain user opinions and feedback. 
c) MIS Implementation: The users are quite enthusiastic about the system being implemented. They help by being active during user training and by quickly making the changes necessary to have the system working. The MIS professionals also implement the system such that the company may quickly start deriving benefits from it.

d) MIS Evaluation: In this case, the eventual system would usually meet the needs of the users. They therefore tend to categorize it as a "success" so that they can continue to benefit from it. The MIS professionals also try to have the system labeled as a "success." They may be expected to do so since they would gain, in terms of both reputation (and therefore influence) and resources, as a result of having developed a successful system.

\subsubsection{The MIS-dominated Process Scenario}

a) Project Proposal: The users strongly resist the proposed system. They use their knowledge of the functional area to try to have the system objectives modified such that it becomes less threatening. Under extreme conditions, they may even try to get the system rejected outright, though they are not likely to succeed in doing so because of their low influence. The MIS professionals actively pursue the system trying to get it quickly accepted. They also try to get funding and resources (c.g., more staff and equipment) to increase their own power.

b) MIS Design and Development: The users withhold information during requirements analysis to adversely affect the system and also increase their own power through their knowledge of the problems the system would have as a result. They try to have the system designed such that it becomes less threatening. Their contribution here is very passive (Keen 1981). Being more influential in this case, the MIS professionals may try to dominate the users by appealing to the topmanagement to intervene. They may try to appease the users through such tactics as greater user involvement or by trying to reduce the threat the system poses to the users (mutual negotiation). MIS professionals may also design the system such that it provides them with greater access to privileged information, thereby helping them gain power.

c) MIS Implementation: The users continue to strongly resist the system, trying to deflect its goals and diverting resources, by playing political games (Keen 1981; Grover, Lederer and Sabherwal 1988). The MIS professionals actively push the implementation process. Again, they may either take a confrontational posture towards the users and appeal to authority or take a more reconciliatory approach trying to negotiate with and involve them. d) MIS Evaluation: Here the users would try to have the threatening system labeled a "failure" and, if possible, discontinued. The MIS professionals would try to get the system rated as a "success" so that they can benefit from having developed a successful system, and also benefit from the system's continued operation (and the resulting funding for staff and equipment).

\subsubsection{The User-Dominated Process Scenario}

a) Project Proposal: The users are actively involved in this stage. Using their knowledge of the functional area, they try to modify the system objectives such that its threat to them is reduced. Under extreme conditions they may even try to get the system rejected outright. The MIS professionals contribute passively ("foot dragging"). They may use their technical expertise to try and adhere to the system's "rational" objectives which the users are opposing or may comply with the users in reducing the threat the system poses to them.

b) MIS Design and Development: The users try to have the system designed such that their own power bases are maintained or enhanced (Franz and Robey 1984) and may ask "what's in it for us?" Furthermore, they may try to keep the other users out to benefit politically with respect to them. Here again, the MIS professionals may use their knowledge of the technical aspects of the system to adhere to "rational" goals and resist users' parochial moves or may "give in" to the users. They may also use their expertise to so design the system that they have greater access to privileged information, thereby gaining power. In some extreme cases, the MIS professionals might even leave the company (Franz and Robey 1984; Mintzberg 1983).

c) MIS Implementation: In case the users have been successful in biasing the system for their departmental goals, they would actively support its implementation. Otherwise, they may either try to deflect system goals (Bardach 1977) or strongly resist it. The MIS professionals continue to contribute passively and are not very enthusiastic and innovative. They may also continue their attempt to achieve greater access to privileged information through this system.

d) MIS Evaluation: Here also, the behavior of the users would depend on what has gone on in the earlier stages. Thus, if they have succeeded in having the system favorably modified, they would try to have it categorized as a "success." On the other hand, if they have not succeeded in their attempts, they may call it a "failure" and even try to get it discontinued. The MIS professionals may continue to take a "rational" approach or, if there has been mutual negotiation with the users, they may label it a "success" due to the 
feeling that they may benefit from having contributed to a successful system.

\subsubsection{The Conflict Process Scenario}

a) Project Proposal: The users are actively involved here. They strongly resist the proposed system, using their knowledge of the functional area, and try to get the system modified such that it becomes less threatening. Under extreme conditions they may even try to get the system rejected outright. The MIS professionals actively pursue the system, trying to get it quickly accepted, so that they, and the organization, may benefit from it. They use their technical expertise to try to adhere to the system's corporate objectives which the users are opposing.

b) MIS Design and Development: The users try to control the system development process. They withhold information during requirements analysis to hurt the system. They try to make the system less threatening, while simultaneously trying to increase their own influence on the system to maintain or enhance their power bases (Franz and Robey 1984), and may negotiate with MIS and other parties for this purpose (Markus and Bjørn-Andersen 1987). The MIS professionals may respond to the users' withholding information in several ways. They may do so by using their technical expertise or by appealing to top management to intervene. They may also give the impression that they are trying to involve the users and that the users are strongly opposing the system. They may negotiate with the users and actually involve them.

c) MIS Implementation: If there has been mutual negotiation between the users and MIS and the system has been modified to the users' satisfaction, they would support its implementation. Otherwise, they would indulge in game-playing, resisting the system by trying to deflect its goals and diverting resources (Keen 1981; Grover, Lederer and Sabherwal 1988). The MIS professionals actively push the implementation process and may appeal to top management in case the users continue to resist. Or if the users are not strongly resistant, there may be negotiations, even at this somewhat late stage, between them and the MIS professionals. In extreme conditions some MIS professionals may leave the company.

d) MIS Evaluation: The users would try to have the threatening system labeled a "failure" and, if possible, discontinued if they feel that it would threaten their power bases. However, if they have been able to have the system favorably modified, they may try to have it categorize as a "success." The MIS professionals would usually try to get the system rated as a "success" so that they can benefit, politically and in terms of resources, from it.

\subsection{Comments}

Some general characteristics of the four process scenarios have been presented. Two important points about these scenarios need to be mentioned. First, the descriptions represent relatively "pure" portrayals of the scenarios. Therefore the ISD process for any given system may be close to one of these scenarios but may not exactly fit any of the pure forms.

Secondly, the ISD process may start off representing one process scenario but may later change to another scenario. Changes may take place in the contextual factors causing a shift from one process scenario to another. Thus users, who did not perceive the system to be a threat earlier, may believe after the design phase that it can affect them adversely, and thus a shift from the "co-operation" to the "conflict" scenario might occur. Similarly, the MIS department, relatively powerless during earlier phases of the ISD project, may become much more powerful (for example, because of a new CEO who strongly believes in the potential of MIS) causing a change from the "user-dominated" scenario to the "MIS-dominated" scenario. The case of Gamma, presented in Section 3, illustrates such a shift from one process scenario to another.

\section{CASE STUDIES}

In this section, three case studies of ISD processes are presented. While the first two cases are examples of "cooperative" and "MIS-dominated" process scenarios respectively, the third case shows how there may be a shift from one process scenario to another during the ISD project and also serves to illustrate the "user-dominated" and "conflict" scenarios.

\subsection{A Case Illustration of the Co-operative Process Scenario}

Alpha, a large insurance corporation, was automating its claims processing system to replace a manual one. The project was from the outset a co-operative joint venture between the MIS department and the Claims department. The motivation behind the change was economic with an estimated payback of within two years of using the system. At the time of the study, the system was being pilot tested in two branches.

\subsubsection{Perceived Threat to Users}

a. Uncertainty: Although it was possible for the new system to increase workloads temporarily, it was estimated this would decrease once the whole system was installed. Staff was assured that no one would be let go because of the new system. Like many insurance corporations, the clerical staff was not unionized 
and was vulnerable in this respect. However, in common with other similar companies, Alpha prided itself with looking after its employees. Job losses would be handled by attrition and slack taken up by increased volume and productivity.

b. Conscious Attempts to Control: There appeared to be no conscious effort to control in this case. The joint venture was to enhance the field office work without destroying the loose reporting relationship to the head office.

c. Organizational Invalidity: The system was designed to fully support the decentralized branch offices. They were the ones who would benefit from the staff savings. The system and the organization were in full harmony in this respect.

d. Historical Factors: Although previous systems were not considered by the users to be threatening, there was a strong impression that many of these systems were originated by MIS, technically oriented, and were cumbersome to use. This joint, co-operative approach was a conscious effort to find a new way of developing more user-oriented systems.

\subsubsection{Relative Power of MIS and Users}

It appears that in all the dimensions of relative power neither side dominated the other. For example, for the system to be successful, both sides had to share their privileged information. The users shared their claims knowledge and MIS pooled their technical expertise on networking, as the system used a complex, distributed processing configuration. There appeared to be a will on both sides to succeed.

\subsubsection{Information System Development Process}

a. Project Proposal: The project originated with the users who acknowledged the need for joint development with MIS and a change in the previous systemsled projects which had proved disappointing.

b. MIS Design and Development: This moved briskly and according to schedule. As mentioned above, there was extensive user involvement and a major effort was put into "designing the new environment" for the claims system. For example, a prototype model claims office was built with new furniture and computers in order to design a suitable environment and train the claims staff. Additionally, new staff positions were created to interface between the systems and users.

c. MIS Implementation: There was a great deal of excitement and expectation concerning the new system among branch staff. When the system was initially introduced first for one insurance function and then for others, a technical problem occurred which forced curtailment of implementation. The full load on the system caused unacceptable response times under certain conditions. This led to considerable disappointment among those staff members who had been trained for the new system but would now have to suffer several months delay. At the time of study, this problem had not been resolved although there was clearly a will to succeed by both parties.

d. MIS Evaluation: Not yet done.

\subsection{A Case Illustration of the MIS-Dominated Process Scenario}

Beta is a small but rapidly growing insurance corporation with its home office in New England. Its 18 branches are mainly in the Northeast but extend as far as the West Coast. It handles only insurance underwriting and deals with the public through a network of agents.

Computerization of personal lines insurance had gone relatively smoothly in Beta because of the essentially structured, rule-based nature of the task. Commercial policies were all manually rated and issued in 1982. Gradually, however, policies which were more homogeneous and more standardized were also rated and issued on the computer. This case describes the process of introducing a commercial lines insurance system. Although computing and systems were developed centrally at head office, the branches were highly autonomous. Underwriting managers had a great deal of discretion over issuing and pricing policies and branch managers had high status at Beta. Each branch was a profit center.

\subsubsection{Perceived Threat to Users}

a. Uncertainty: Commercial underwriters were high status employees at Beta compared to personal lines underwriters. There was a fear among some underwriters that computerization might eventually "deskill" the craft-like nature of their work. However, it was also felt that computing could never totally replace the commercial underwriter, whose task is characterized by variety, pressure and high levels of discretion.

b. Conscious Attempts to Control: The proposed system had built in an element of monitoring and control. The head office auditing function was very important to ensure that the procedures had been followed and documentation completed. Before computerization was introduced in Beta, the commercial underwriters enjoyed great flexibility in offering accounts to the auditor together with explanations for any discrepancies. With computerization it was felt that the auditors could randomly select accounts and the 
underwriter would not be given the opportunity to explain any shortcomings.

c. Organizational Invalidity: The branches were highly decentralized yet this monitoring and control function cut inroads into branch autonomy. The new system also imposed rigid requirements on the renewal of policies again a feature that previously had been determined by the underwriters themselves.

d. Historical Factors: These did not seem significant in this case. One of the New England branches in the study had only been established in the early 1980s.

\subsubsection{Relative Power of MIS and Users}

The key factor here was the system group's access to top management at the head office. It appeared that the commercial lines system was jointly conceived by these parties. Although the skill of the commercial underwriter was valued by the corporation as a way of coping with uncertainty, the same could be argued for the value of the systems group.

\subsubsection{Information Systems Development Process}

a. Project Proposal: It appeared that the proposed system was conceived by the MIS group and the head office. No evidence was found for extensive user involvement at this stage.

b. MIS Design and Development: Several underwriters from the branches were co-opted into the project team to represent their function. However, it was felt in the branches that these surrogates quickly became "systems people" as they imbibed that culture. Until the system was implemented there was no other user involvement and users were not informed about the systems capabilities and potential effects. The process of design had been centralized with only minimal branch input.

c. MIS Implementation: This was the first time most of the users saw the underwriting system. It seemed to be poorly introduced with minimal training and documentation. At several branches there was strong resistance to the system. There were severe technical flaws. The screens were considered "unfriendly," the reliability was suspect and the response time varied but was up to several minutes for some situations. Because the system did not match the underwriters needs and work patterns, many of them continued with their largely manual system, taking every opportunity to bypass the computer system. The commercial insurance manager at one branch had his personal computer removed from his office indicating his lack of support for the new system.

d. MIS Evaluation: Although nominally implemented, the system would be judged a failure by those underwriters who avoided it wherever possible. It was interesting that branch autonomy was such that users could choose to adopt it or reject it. However, at the time of study, there were indications that users would have to be coerced into using it -- a further indication of a subtle change in corporate culture.

\subsection{A Case Illustration of Shifts between Process Scenarios}

Gamma is a large public university in New England. The system in question was Thruway, a computerized admissions system, which was being introduced as the front end to a comprehensive Student Information System. Thruway replaced individual tape-based batch systems, which from the university's perspective were inadequate, particularly for the recruiting function. This function was increasingly important as Gamma was suffering from declining numbers of applicants. Thruway was seen by the senior administrators as a way to coordinate this effort across the university. The development began with undergraduate admissions, the largest admissions unit in the university.

\subsubsection{Perceived Threat to Users}

a. Uncertainty: The users in undergraduate admissions were relatively content with their current batch system even though it had technical drawbacks. They were therefore somewhat uncertain about a new system, especially as it involved new technology (on-line) about which they were not knowledgeable. However, this did not appear to be a decisive factor overall.

b. Conscious Attempts to Control: The conception of the system did not appear to offer any conscious threat nor was any perceived by the users.

c. Organizational Invalidity: The system was designed to standardize admissions across the university and integrate the system with the Student Information System at a later date. This ran counter to the university structure which, like many organizations of this type, was decentralized or loosely-coupled (Weick 1976). This generated considerable friction when users from different units sat down together to try and agree on system requirements.

d. Historical Factors: The pattern of MIS development was broken by Thruway, which was much larger than the previous systems attempted by the systems group. There also appeared to be little experience of this type of system among the systems staff. Additionally, a new 
director of undergraduate admissions was appointed just before development took place. Not only was she computer-literate, she was also politically skillful. Finally, the computer center was using a third party co-developer for the system, who, because they wished to market the system elsewhere, imposed quite severe design constraints on Thruway.

Although the perceived threat to the users appeared to be quite low, the potential threat from the organizational form and historical precedents proved decisive in this case as they both helped to structure conflict into the process (Newman and Noble 1988).

\subsubsection{Relative Power of MIS and Users}

a. Privileged Information: While the systems group had privileged technical information, undergraduate admissions were vital to the project's development. They were the largest and the first unit to be computerized. There seemed no relative advantage here.

b. Privileged Access to the Influential: Undergraduate admissions had an advantage over the systems group. The new director came in with a mandate to improve undergraduate recruitment (a key factor in the university's success). She also had the "ear" of the Vice President of administration, a factor which would prove decisive in subsequent events.

c. Non-substitutability: There appeared to be no relative advantage. Each party needed the skills and cooperation of the other. Systems had no choice but to use undergraduate admission as a pilot.

d. Coping with Uncertainty: The systems group had some strength as they could help the university cope with a major source of uncertainty through an on-line recruiting/admissions system. However, undergraduate admissions were also vital in this task and systems could not proceed without them.

e. Political Will and Skill: Undergraduate admissions had a decisive advantage over systems. Not only was the director of admissions skillful politically, she had a clear strategy. The project leader from systems appeared worse off on both these counts.

\subsubsection{Information Systems Development Process}

a. Project Proposal: This was agreed at a top management level in the university. No one seemed to know of any budget for the new system. Users appeared to be only minimally represented at this stage. This does not follow the proposed scenario. b. MIS Design and Development: Initially the users from undergraduate admissions co-operated fully in the information requirements analysis stage and they eventually signed off on the system. In the meantime, a project team from around the university had been trying to agree on standards for the new system. This involved two policy statements, one for the database contents and another for access to the data. Considerable friction was generated in these meetings with the representatives from different groups "going for the jugular," as the chairman expressed it, and reacting in a proprietary manner concerning ownership and control of data. This conflict would be consistent with the lack of fit between the system and the organization.

When undergraduate admissions first saw the test system as designed, they had two major complaints: there were too many screens and the screens changed too slowly. The project leader first attempted persuasion, then threats and appeals to a higher authority to compel the users to accept the system. There was little or no effort to accommodate the users' demands. The issue was finally resolved by a decisive move by the undergraduate admissions director who called upon her political capital through the Vice President to force MIS to change. Eventually MIS redesigned the system and accommodated the user demands.

c. MIS Implementation: The system was eventually implemented relatively successfully for undergraduate admissions. However, it appeared that because the system group had capitulated to them, the users were now able to demand and obtain enhancements to undergraduate admissions in the form of a recruitment module. Instead of moving on to other user groups with Thruway, the systems group had been "captured" or dominated by the admissions group and this was the situation at the time of study. The systems group was not very enthusiastic about the system, which they saw as fragmented like the rest of the organization. Other units began to get frustrated and started developing their own systems.

d. MIS Evaluation: From the users' (undergraduate admissions) perspective, the new system worked well and they were getting all the help they wanted. From perspective of the systems group and the university, it was more problematic. The original systems design was being submerged by parochial interests. It was as if the organization was squeezing the system until it conformed to the existing structure.

In this case, the system did not start off as a threat to the users. However, organizational invalidity and internal problems, along with the project leader's attempt to dominate users, resulted in considerable increase in the system's perceived threat to users. This change in an important contextual factor implied that 
the ISD project, which started out as a co-operative venture, moved to a highly conflictual picture resolved in favor of the users, who subsequently dominated the process.

\section{DISCUSSION}

A process model for the control of information systems development projects has been introduced. Using the dimensions of perceived threat to users and relative power of systems/user groups, we constructed four scenarios across various stages. These "pure forms" were then illustrated with summaries from three case studies.

The model emphasizes the need to consider both the behavior of individuals during the project and the contextual factors associated with the project. By analyzing the process of system development, we can see that each episode may result in decisions or behaviors which constrain subsequent developments (Cobb 1984). For example, user resistance is a behavior which can, and often does, arise when systems are introduced. How user resistance is dealt with can be critical for future actions. Thus, viewing resistance as an illicit behavior which needs to be eradicated could fail to recognize users' genuine problems with the new design. Coercing users in such circumstances would be counter-productive. However, individual behavior is insufficient to understand the sequence of events. For this we need to give full recognition to the context, which is related to the threat to the users by the system and to the relative power of the systems group and the users.

This approach allows us to see that some projects are virtually assured of failure before they even begin (cf. Naumann, Davis and McKeen 1980). Not only do they pose a severe threat to users (for example, because of historical patterning), but the power balance between the parties also ensures a highly conflictual design process. Clearly this has important economic consequences for the organization and if the project was begun it would require a concerted effort to overcome such barriers.

While the contextual factors thus influence the ISD process, they may themselves change over time. We therefore do not claim that the process model is deterministic. The actions (or inactions) of the parties during the design stages can be vital in influencing the course of events. ISD processes can, and often do, shift from one process model to another. Such shifts can be viewed as consequences of the changes in the contextual factors. The model thus takes a dynamic perspective and suggests that being continuously sensitive to these factors should pay rich dividends for the project leader.

Although we present the four "pure" scenarios, we recognize the possibility of hybrid processes. For example, in Gamma (the university), the process began as a co-opera- tive venture between systems and users. The users reacted negatively with strong resistance when they first saw the test system. This resulted in a confrontation between the systems and user groups with a series of threats, counterthreats, coercion and then a resolution by appeal to higher authority. The process thus finally shifted from the conflict scenario to the user-dominated scenario after the users had secured "victory" in the battle with the system group.

The model also throws into doubt the question of "successful" systems. Not only would an assessment of success change over time, it would also vary with who you asked, particularly in a win/lose situation. This can be seen especially clearly in Gamma, where the users "won" and secured design changes for their particular unit. From the organization's perspective, success was more problematic in that while the systems design was proceeding it was becoming more parochial rather than corporate, as had been originally conceived. The systems group, who valued the integrated approach, were alarmed by this turn of events but were not powerful enough to prevent it.

Using a process model makes simple design prescriptions irrelevant or dangerous. Our model and scenarios should be useful to designers and researchers in helping them see the possibilities for development strategies. It must be left to the designers and users to analyze their specific situations and historical context in terms of the above model and then to assess the likelihood of a particular scenario developing. In particular, the designer would do well to realistically assess the previous patterns of relationships in projects. If the assessment reveals a history of conflict between designers and users, then we should be prepared for a similar pattern to be reproduced in the current project. ${ }^{2}$ To change this pattern would require extra effort on the designer's part. If the framework offered here can assist in this process, and thus contribute to improving future ISD, the paper would have adequately served its purpose.

\section{ACKNOWLEDGEMENTS}

The empirical work cited in this paper was supported by the Economic and Social Research Council, U.K. (Grant Number F0023 2269). The authors would like to thank Chris Kemerer and the anonymous reviewers for their helpful comments in preparing this article.

\section{REFERENCES}

Bardach, E. The Implementation Game: What Happens After a Bill Becomes a Law, Cambridge, Massachusetts: MIT Press, 1977.

Bariff, M. L., and Galbraith, J. R. "Intraorganizational Power Considerations for Designing Information Systems." 
Accounting, Organizations, and Society, Volume 3, Number 1, 1983, pp. 15-27.

Boland, R. J., Jr. "The Process and Product of System Design." Management Science, Volume 24, 1978, pp. 887 898.

Cobb, A. T. "An Episodic Model of Power: Toward an Integration of Theory and Research." Academy of Management Review, Volume 9, Number 3, 1984, pp. 482-493.

Franz, C. R., and Robey, D. "An Investigation of UserLed System Design: Rational and Political Perspectives." Communications of the $A C M$, Volume 27, Number 12, December 1984, pp. 1202-1209.

Gladden, G. "Stop the Life-Cycle, I Want to Get Off." Software Engineering Notes, Volume 7, Number 2, 1982, pp. 35-39.

Grover, V.; Lederer, A. L.; and Sabherwal, R. "Recognizing the Politics of MIS." Information and Management, Volume 14, 1988, pp. 145-156.

Hirschheim, R.; Klein, H.; and Newman, M. "Information Systems Development as Social Action: Theory and Practice." Working Paper, University of Houston, Under Submission, 1988.

Hirschheim, R., and Newman, M. "Information Systems and User Resistance: Theory and Practice." The Computer Joumal, Volume 31, December 1988, pp. 398-408.

Hirschheim, R., and Newman, M. "Symbolism and Information Systems Development: Myth, Metaphor and Magic." Working Paper, University of Houston, Under submission, 1989.

Hickson, D. J.; Hinings, C. R.; Lee, C. A.; Schneck, R. E.; and Pennings, J. M. "A Strategic Contingencies Theory of Inter-Organizational Power." Administrative Science Quarterly, Volume 16, Number 2, 1971, pp. 216-229.

Ives, B., and Olson, M. H. "User Involvement and MIS Success: A Review of Research." Management Science, Volume 30, Number 5, May 1984, pp. 586-603.

Keen, P. G. W. "Information Systems and Organizational Change." Communications of the ACM, Volume 24, Number 1, January 1981, pp. 24-33.

Lawrence, P. R., and Lorsch, J. W. Organizations and Environment, Boston: Division of Research, Harvard Business School, 1967.

Lucas, H. Why Information Systems Fail, Columbia University Press, 1975.
Lyytinen, K. Information Systems Development as Social Action: Framework and Critical Implications, Ph.D. Thesis, University of Jyvaskyla, Finland, 1986.

Lyytinen, K., and Hirschheim, R. "Information Systems Failures: A Survey and Classification of the Empirical Literature." Oxford Surveys in Information Technology, Volume 4, 1987.

Markus, M. L. "Power, Politics, and MIS Implementation." Communications of the $A C M$, Volume 26 , Number 6, June 1983.

Markus, M. L., and Bjørn-Anderson, N. "Power Over Users: Its Exercise by System Professionals." Communications of the $A C M$, Volume 30, Number 6, 1987, pp. 498504.

Markus, M. L., and Pfeffer, J. "Power and the Design and Implementation of Accounting and Control Systems." Accounting, Organizations, and Society, Volume 8, Numbers 2/3, 1983, pp. 205-218.

Markus, M. L., and Robey, D. "The Organizational Validity of Management Information Systems." Human Relations, Volume 36, 1983, pp. 203-226.

Mintzberg, H. Power In and Around Organizations, Englewood Cliffs, New Jersey: Prentice-Hall, 1983.

Mumford, E., and Pettigrew, A. Implementing Strategic Decisions, London: Longman, 1975.

Naumann, J. D.; Davis, G. B.; and McKeen, J. D. Joumal of Systems and Software, Volume 1, 1980.

Newman, M. "Folklore in ISD: Some Counter Evidence." In R. Jeffery, Editor, Proceedings of the Second Joint International Symposium on Information Systems, Sydney, Australia, 1988, pp. 87-106.

Newman, M., and Noble, F. "User Involvement as an Interaction Process: A Case Study." Working Paper, Department Accounting and Finance, University of Manchester, 1988.

Newman, M., and Rosenburg, D. "Systems Analysts and the Politics of Organizational Control." OMEGA, Volume 13, Number 5, 1985, pp. 393-406.

Saunders, C. S. "Management Information Systems, Communications, and Departmental Power: An Integrative Model." Academy of Management Review, Volume 16, Number 3, 1981, pp. 431-442.

Saunders, C. S., and Scamell, R. W. "Organizational Power and the Information Services Department: A Reexamination." Communications of the ACM, Volume 29, Number 2, February 1986, pp. 142-147. 
Swanson, E. B. "Rationality and Politics in Information System Design and Implementation: A Juxtaposition of Two Views." Accounting Onganizations and Society, Volume 8, Numbers 2/3, 1983, pp. 219-221.

Tait, P., and Vessey, I. "The Effect of User Involvement on System Success: A Contingency Approach." MIS Quarterly, Volume 12, 1988, pp. 91-108.

Weick, K. "Educational Establishments as LooselyCoupled Systems." Administrative Science Quarterly, Volume 21, Number 1, March 1976, pp. 1-11, 19.

\section{ENDNOTES}

1. There is, of course, no limit to the description of the context for the change process. The two factors we have chosen are, we believe, broad enough to cover the main issues of contextual importance.

2. Moreover, to allow conflict to develop and proliferate without being dealt with during the project could have serious implications for future development work as well. 